\title{
Uma Reflexão do Modelo de Espaço Público Habermasiano
}

\author{
[ A Reflection of the Habermasian Public Space Model ]
}

\author{
José Ronaldo de Oliveira Marques * \\ Universidade Federal da Paraíba, Brasil
}

\begin{abstract}
Resumo: O presente artigo tem como finalidade investigar o conceito de espaço público ou Öffentlichkeit em Habermas, como principal foco a análise e a crítica da política burguesa que, segundo o autor, reordenou o modelo de poder e de economia na sociedade Ocidental, como também a ideia de publicidade. Assim o desenvolvimento desta reflexão se situa a partir do próprio esforço que Habermas fez na sua obra inaugural sobre o espaço público em Mudança Estrutural da Esfera Pública (2003), desenvolvendo uma genealogia e um conceito de espaço público que ampliou a ideia de democracia. Habermas investigou também a natureza do espaço público político burguês que conquistou poder e ascensão social. A análise habermasiana da esfera pública diz respeito, ainda as mudanças políticas, sociais e econômicas que desenharam uma nova estruturação da sociedade entre os séculos XVIII e XX, principalmente com o advento da burguesia. Tal estruturação levou a um novo ordenamento jurídico do espaço público com leis que garantiram não só a circulação de mercadorias, mas de ideias. Com efeito, o deslocamento do poder para a burguesia gerou também mudanças na divulgação de outras ideias. No entanto, a publicidade burguesa recebeu nuances tendenciosas fazendo da imprensa um veículo de manipulação das massas. Partindo desta reflexão analisaremos a publicidade como fomentadora de uma ideologia burguesa que recebeu críticas do autor. Falar de espaço
\end{abstract}

ABSTRACT: This article aims to investigate the concept of public space or Öffentlichkeit in Habermas, focusing on the analysis and criticism of the bourgeois politics which, according to the author, reorganized the model of power and economy in Western society, as well as the idea of advertising. Thus the development of this reflection is based on the very effort that Habermas made in his inaugural work on the public space in Structural Transformation of the Public Sphere (2003), developing a genealogy and a concept of public space that extended the idea of democracy. Habermas also investigated the nature of bourgeois political public space that gained power and social ascension. The Habermasian analysis of the public sphere also concerns the political, social and economic changes that have drawn a new structure of society between the eighteenth and twentieth centuries, especially with the advent of the bourgeoisie. Such structuring led to a new legal system of the public space with laws that ensured not only the circulation of goods, but also of ideas. In fact, the shift of power to the bourgeoisie also generated changes in the dissemination of other ideas. However, bourgeois advertising received biased nuances making the press a vehicle for mass manipulation. Starting from this reflection we will analyze the publicity as a promoter of a bourgeois ideology that received criticisms from the author. To speak about public space is also to speak about the role of the citizen of the state which, according to Kantian philosophy, is 
público é falar também do papel do cidadão de estado que, de acordo com filosofia kantiana, é vista a partir da ideia de concordância pública, em Hegel com a opinião pública. Já em Marx o papel do cidadão se dá pela emancipação política do proletariado. $O$ papel do cidadão no modelo de espaço burguês fica fragmentado, pois ele perde suas capacidades comunicativas como consequência da burocratização estatal. Este modelo fragmentado é visto a partir da relação antagônica de "sistema" e "mundo da vida", tratando a política como poder de barganha. Por fim, uma ideia de esfera pública livre e independente é central para a democracia deliberativa que tem como princípio resguardar as capacidades comunicativas dos cidadãos com o intuito de chegar a ideia de bons argumentos.

Palavras-chave: Burguesia; Democracia deliberativa; Espaço público seen from the idea of public agreement, in Hegel with the public opinion. Besides, in Marx the role of the citizen is given by the political emancipation of the proletariat. The role of the citizen in the bourgeois model of space is fragmented, as he loses his communicative capacities as a consequence of state bureaucratization. This fragmented model is seen from the antagonistic relationship of "system" and "world of life", treating politics as bargaining power. Finally, an idea of a free and independent public sphere is central to deliberative democracy, whose principle is to protect the communicative capacities of the citizens in order to come to the idea of good arguments.

KEYWORDS: Bourgeoisie; Deliberative democracy; Public space

\section{INTROUÇão}

ideia de espaço público remonta aos tempos da Grécia antiga quando, em A Atenas, as discussões públicas e destinos da polis eram feitas na àgora em praça pública. No entanto, só os cidadãos livres podiam participar dos destinos da cidade-estado. Esta ideia de igualdade de condições para falar e discursar possuía os seus limites impostos pela condição social. A democracia ateniense não era perfeita e o espaço destinado a opiniões e ideais era restrita aos homens livres, ficando de fora mulheres, crianças, escravos e estrangeiros. As falhas da democracia ateniense estão bem além de uma concepção política e de democracia que dava amplos poderes de participação e os direitos de isonomia e isegoria aos cidadãos.

Habermas (2003) fez um grande estudo em torno da ideia de espaço público. Ele analisou e investigou as origens, bem como as transformações sociais que aconteceram na Europa da transição do modelo de economia e política feudal, que tinha suas bases na pequena família, para um modelo público político burguês de circulação de mercadorias e de ideias.

O autor de a Strukturwandel der Öfenlichkeit (Mudança Estrutural da Esfera Pública) buscou fazer uma delimitação do tipo de esfera pública que nos séculos XVIII, XIX e XX se afirmou como sendo de natureza burguesa. Ele definiu, em primeiro lugar, o conceito de público que está ligado ao poder do estado e ao bem comum dos cidadãos e, ainda, define o conceito de publicidade (publizität) como uma opinião do interesse comum a todos, distinguindo também o público do privado. Este modelo tem suas origens na versão greco-romana da polis dos cidadãos livres com a sua autonomia e o uso da liberdade se desenvolvendo na bios politikos, ou seja, na vida pública. Mas, para os gregos, a democracia era seletiva e só alguns podiam participar da vida política com a sua representatividade.

O modelo de representatividade pública que alcançou a Idade Média era, principalmente, centrada no modelo das virtudes aristotélicas que tinha como objetivo alcançar a eudaimonia (felicidade) buscando o equilíbrio na medida das coisas e não nos excessos, pois segundo a ética aristotélica a virtude está no meio. ${ }^{1}$ 
No entanto, este modelo ético foi perdendo força e legitimidade. Esta representatividade se baseava na relação de economia doméstica do poder privado, do governo do oikos ou pater-familias. Era um poder que tinha como sua base de sustentação a terra e o campo, um poder tipicamente fundiário e uma economia doméstica.

Com a ascensão da burguesia inaugura-se um novo modelo de representatividade, onde o antigo e medieval sucumbira. $\mathrm{O}$ novo modelo burguês de representatividade tem como base a circulação de mercadorias e dinheiro, bem como informações. Esta foi uma das causas do seu desenvolvimento, pois englobou toda a sociedade em termos econômicos e políticos.

Portanto, com o novo modelo de sociedade, a burguesia assume o papel na construção de espaço público e foi crucial para criar também uma ideia de publicidade e informações comuns a todos. Como consequência possibilitou e ampliou também liberdades e conquistou direitos. Os direitos burgueses foram disseminados, como de se expressar a opinião e de almejar também diretos de natureza políticos e de terem os seus direitos garantidos de forma ampla. A maior conquista dos burgueses foi a liberdade de opinião e de associação. 1) os direitos burgueses podem ainda ser divididos em três partes: os direitos relativos a esfera privada que são liberdade de opinião e de expressão, liberdade de imprensa, liberdade de associação e de reunião; e ainda com a sua função política com direito a pedir e votar; 2) os chamados direitos básicos que são: liberdade individual, inviolabilidade do local de residência; 3) que diz respeito a propriedade privada igualdade perante a lei e proteção da propriedade privada.

Por conseguinte, o modelo de Öffentlichkeit ou espaço público permitiu além dos direitos aos burgueses uma melhor circulação de ideias e pensamentos. Por outro lado, segundo Habermas, o espaço público burguês assumiu cada vez mais características políticas, mas de uma política ligada ao mercado juntamente com os fundamentos de uma publicidade tendenciosa que favoreceu aos sistemas a colonização do mundo da vida.

$\mathrm{O}$ autor, como um dos representantes da teoria crítica, sempre pressupôs uma ideia de esfera pública livre com a racionalidade comunicativa que exortava a ideia do bom argumento. A esfera pública deve ser livre e independente e, consequentemente, obriga o diálogo entre os afetados pelo discurso. Também uma esfera plural abriga ideias diferentes, como ideologias e crenças, permitindo que os cidadãos crentes, não crentes, agnósticos, ou qualquer que queira se expor, levar em conta o mediun do direito. São ideias fundamentais para fortalecer o conceito de Estado de direito democrático.

\section{A Origem do EspaÇo Público burguês}

O desenvolvimento do capitalismo mercantil cresceu nas cidades europeias em meados do século XV e XVI e, com a expansão das atividades econômicas e comerciais, possibilitou a alavancada da burguesia. Com esse crescimento uma perspectiva de espaço público burguês se concretiza. O Öffentlichkeit ou espaço público burguês expandiu não só a liberdade de negócios e a livre passagem das mercadorias, como também a troca de ideias e de informações.

As cidades e os mercados foram se expandido e com isso as trocas de informações. As grandes navegações marítimas do além-mar juntamente com a impressa de Gutenberg revolucionaram a proliferação de notícias. Com isto, um novo 
sistema de informações nas cidades foi se aperfeiçoando.

Segundo Habermas, a troca de informações seguiu o mesmo caminho das mercadorias negociadas no comércio que se expande nas cidades, como ele afirma:

Algo semelhante ocorre com a troca de informações que se desenvolve na trilha da troca de mercadorias. Com a expansão do comercio, o cálculo comercial, orientado pelo mercado, precisava, de modo mais frequente e exato de informações sobre eventos espacialmente distanciados. (HABERMAS, 2003, p. 29).

O espaço público burguês possibilitou cada vez mais o surgimento de novas ideias criando uma esfera de renovação política e econômica.

A política, era aos poucos substituída pelos ideais democráticas que tiveram o seu ápice nas revoluções Americana de 1776 e Francesa de 1789. Este espírito de liberdade se espalhou por toda a Europa. Na Inglaterra, berço da revolução Industrial, mantinha um modelo constitucionalista. Já não nutria a política de um poder monárquico e absolutista a tempos, como Habermas (2003, p. 42) sublinha: "Na Inglaterra, reconhecidamente, com a relativização do poder real pelo parlamento, esta evolução assume um outro curso do que com a mediação dos estamentos pelo monarca no Continente europeu".

Em continuação, os burgueses conseguiram aos poucos ocupar os espaços que antes eram da monarquia e da nobreza. Os salões, clubes e cafés passaram a ter papel fundamental na transmissão de informações e de novas ideias, permitindo uma verdadeira revolução no campo da publicidade e da opinião pública com uma impressa livre.

Essas mudanças se deram com a reformulação artística e cultural do século XVIII e XX. A corte vinha cada vez mais perdendo sua posição na esfera pública. $\mathrm{O}$ salão do palácio foi substituído pela cidade que passava a ter papel importante nas manifestações artísticas e culturais. A esfera pública, a partir da cidade, ganhou uma nova conotação, pois nela foi transferida a representatividade da antiga nobreza que perdeu força e poder. Com isso, o acesso à cultura não ficava mais restrito a nobreza, mas a outras classes. Habermas (2003, p. 47) assevera que "à medida que 'a cidade' assume suas funções culturais, modifica se não só o sustentáculo da esfera pública, mas ela mesmo se modifica".

As novas instituições são ambientes naturais aos debates, não ficando restritos apenas à crítica literária, mas também aos debates políticos. E porque não dizer também as questões próprias da liberdade e do agir dos indivíduos.

Os cafés e os salões, como parte dessas novas instituições, possuíam um espirito mais democrático do que os lugares da antiga nobreza, pois iam incluindo mais pessoas nas discussões e nos debates públicos. Com as revistas não foi diferente. Elas foram aos poucos introduzidas na vida das pessoas, com novas ideias e começaram, a partir do crescimento da impressa, a ter uma maior circulação. Também passaram a ser instrumentos de crítica literal, religiosa e política.

Os jornais impressos são os meios de transmissão de informações mais populares e são utilizados como o intuito econômico e comercial, mas também político. A imprensa criou um verdadeiro ambiente intelectual e cultural fortalecendo cada vez mais a publicidade burguesa.

O ambiente gerou um âmbito democrático que se configura a partir desta ideia de publicidade ou opinião pública, como está descrito na Strukturwandel der Öffentlichkeit, "a publicidade dos debates parlamentares garante à esfera pública a sua influência, assegura a conexão entre deputados e eleitores como partes de um único 
público". (HABERMAS, 2003, p. 104). E recebe cada vez mais inspiração no espaço público de natureza burguês, que também é político, se articulando contra tudo aquilo que atrapalhe o seu projeto de poder.

Não foi à toa que a principal reviravolta política do século XVIII se deu pela pressão que o absolutismo sofrera. Os burgueses, que outrora estavam despidos de poder político, conseguiram aos poucos por meio da opinião pública mudar o jogo, jogando o povo contra a monarquia e exigindo uma constituição e leis que garantissem os amplos direitos de participação política.

Com isso, a opinião pública cai nas mãos da burguesia. Ela passou também a ter forte influência sobre as decisões a serem tomadas. $\mathrm{O}$ desenvolvimento racional das tomadas de decisões foi cada vez mais colocado em prática. E isso chegou as casas legislativas que aprimoraram as leis que beneficiassem os próprios burgueses. As ideais defendidas pelos burgueses giravam sempre em torno de direitos econômicos e políticos. Isso teve como consequência um novo projeto de poder, bem como uma mudança cultural com a nova formulação de espaço público burguês.

\section{O MODELO DE ESFERA PÚBLICA BURGUESA LIMITES E CONTRADIÇÕES}

A esfera pública burguesa é entendida, segundo Habermas, a partir da reunião de pessoas privadas em público. Essas pessoas se reúnem com o propósito de reivindicar seus direitos que foram regulamentados pelas autoridades competentes. Assim, os burgueses buscavam uma participação direta na política, reivindicando direitos para a garantia da venda e circulação de suas mercadorias e de ideias.

O modelo de esfera pública burguesa, a começar da economia e da circulação de mercadorias substituiu o feudalismo, funcionava a partir das relações de propriedade da terra e a subordinação ao senhor por parte dos servos foi sucumbido. O feudalismo como modelo social era fechado e limitava a ideia de racionalidade pública, por isso a burguesia conquistou espaço com o acesso de informação e participação de todos. Segundo Habermas (2003, p. 105), "uma esfera pública burguesa se rege e cai no princípio de acesso a todos. Uma esfera pública, da qual certos grupos fossem excluídos, não é apenas, digamos, incompleta: muito mais, ela nem sequer é uma esfera pública".

No entanto, esta ideia de uma esfera inclusiva e que abolia qualquer tipo de dominação foi perdendo força para a compreensão de uma institucionalização de normas e a busca de influência da esfera política a fim de proteger a esfera privada com a troca de mercadorias e trabalho social. Isso resultou em uma contradição, pois a busca pelo poder não garantiu mais a acessibilidade para todos, como enfatiza Lubenow (2015, p. 42), “a contradição imanente à esfera pública burguesa não garantia objetivamente que a racionalidade fosse salva às custas de um outro momento, o da generalidade, que garantia a acessibilidade a todos".

O Öffentlichkeit burguês já não garantia mais o interesse comum a todos, mas apenas um jogo de interesses. A ideia burguesa de garantia de direitos e que dava autonomia aos cidadãos não condiz com a sua prática, segundo o qual a esfera pública burguesa não representa a esfera pública de fato. Sua ideologia que era de manter uma racionalidade pública se contradiz na busca de interesses pelo capital e pelo poder.

Esse modelo de poder burguês já havia recebido críticas anteriores pela sua contradição. Tanto Hegel como Marx teceram críticas ao modelo de sociedade burguesa. Hegel compreendia o Estado como o fim da atividade e da vida ética por parte da comunidade, que a forma e se une a sociedade civil e a família. Segundo Hegel 
o Estado não tem apenas uma função administrativa diferente da ideia burguesa.

O Estado burguês ainda é caracterizado por uma visão não política, e uma liberdade individual subjetiva abandonada a contingencia da opinião e da arbitrariedade. Marx realça também essa contradição da burguesia que fala de liberdades, mas em nome dos interesses econômicos e de uma defesa do poder para adquirir vantagens.

Já Kant descreveu uma ideia de opinião pública, ou Öffentlich Meinung, que tem como princípio a mediação entre a política e a moral. Na verdade, para Kant, a política está atrelada a vida moral, pois os nossos atos volitivos devem levar em consideração o Sollen, ou seja, o dever. Para Habermas sustenta essa ideia kantiana de uma racionalidade pública segundo o qual política e moral caminham juntas, e acrescenta dizendo que "por isso é que a 'publicidade' em Kant deve ser considerada como aquele princípio único a garantir o acordo da política com a moral” (HABERMAS, 2003, p. 128).

O fato de Kant naturalizar essa relação de moral política passando pela ideia também do Estado de direito não foi aceita por Hegel, segundo Lubenow (2015, p. 43): "Hegel descobre a profunda divisão da sociedade burguesa: pela sua desorganização (e pela sua condição), a sociedade burguesa é incapaz de dar conta da exclusão que ela cria e esse é o sentido negativo".

Por conseguinte, o modelo de esfera pública burguesa se distanciou de uma ideia de neutralidade frente ao poder e viu seus princípios substituídos pela teoria dos sistemas. Os sistemas, a partir da administração, conseguiram colonizar o lebenswelt ou o mundo da vida. O mundo da vida colonizado teve como consequência a perda da interação, da comunicação entre as pessoas na esfera pública e consequentemente não mais faz a mediação com o Estado. A perda da linguagem pelo sistema e pelos subsistemas do poder e do dinheiro transformou a esfera pública livre e inclusiva em uma esfera pública burguesa excludente que perdeu a sua principal força que é a solidariedade entre os cidadãos.

\section{A ESFERA PÚBICA, O "SISTEMA" E O "MUNDO DA VIDA" COMO CONCEITOS ANTAGÔNICOS}

A esfera pública tem a função de integração social, pois assegura a autonomia do "mundo da vida" frente aos sistemas. Mas o problema da desarticulação da comunicação na sociedade civil resulta ainda de um modelo de espaço público de natureza burguesa que possibilita uma perda dos domínios da linguagem. Isso tem origem nas relações antagônicas entre "sistema" e "mundo da vida" 2 . Esta perda dos domínios da linguagem traz como consequência uma esfera pública despolitizada, onde a democracia funciona a partir do poder administrativo e econômico e não do poder comunicativo.

O "mundo da vida" forma o horizonte com o pano de fundo para a comunicação e a experiência do quotidiano e, com o e contexto tematizado, é levado por acréscimo a formar o polo oposto ao sistema para um saber que é presenciado dentro de seu horizonte de uma representação política participativa. O "mundo da vida" constitui ainda um horizonte de suposições de fundo intersubjetivamente partilhado, no qual todo processo de comunicação precedente está inserido.

Já o "sistema" não tem como princípio a autossuficiência dos sujeitos, tampouco a ação coletiva da sociedade como um todo. No "sistema", os sujeitos não passam de meros observadores passivos, tanto do poder econômico quanto do estatal ou ainda dos 
subsistemas do dinheiro e do mercado. Partido desta ideia contraditória a sociedade é constituída por uma rede de sistemas autônomos que se fecham em relação uns aos outros.

Ainda sobre o conceito de "sistema" formado por um conjunto de elementos delimitados segundo o princípio de diferenciação. Esses elementos, ligados uns aos outros, excluem outros do seu convívio e formam, em relação a estes, um conjunto diferenciado. Todo "sistema" pressupõe, portanto, um mundo circundante com o qual se limita. O mundo é, por hipótese, o que não pertence ao sistema. Ora, se o sistema é um conjunto estruturado, o mundo é, em relação a ele, complexidade, isto é, um conjunto aberto e infinito de possibilidades. Portanto todo sistema é uma redução seletiva de possibilidades em comparação com as possibilidades infinitas do mundo da vida.

Habermas buscou fundamentar um novo modelo de democracia do tipo normativa que é uma terceira via ao liberalismo e ao republicanismo. $\mathrm{O}$ modelo habermasiano de democracia deliberativa é fundamentado a partir do agir comunicativo que vê na razão pública kantiana a forma de se contrabalancear contra o sistema, que embora necessário pode prejudicar a autonomia dos cidadãos.

\section{A ESFERA PÚBICA E UM NOVO MODELO DE DEMOCRACIA DELIBERATIVA}

O modelo de democracia deliberativa na esfera pública leva em consideração o valor do reconhecimento do discurso prático-moral, por isso sua meta também é influenciar as instâncias da administração pública. A democracia deliberativa utiliza a solidariedade como um peso maior para contrabalancear com o domínio sistêmico e se afirmar diante do poder administrativo, dos subsistemas do dinheiro e do mercado. Este paradigma de democracia não tem suas bases na organização sistêmica do tipo políticoadministrativo e sim nas capacidades dialógicas que os cidadãos possuem para chegar ao consenso de ideias.

Para Habermas (1997) o sistema, como uma ideia de racionalização, é de tal forma contraditório que se direciona para as tomadas de decisões. Consequentemente a teoria sistêmica se contrapõe à esfera pública e ao "mundo da vida" que tem peso maior na solidariedade dos cidadãos. A teoria do sistema analisa a sociedade somente a partir do ponto de vista do auto regulação do poder administrativo e, por último, divide o poder entre política e direito e entre vários outros sistemas funcionais que são fechados em si mesmos.

O conceito oposto ao sistema é o do "mundo da vida" que se mantém em forte interação com o cotidiano e com a vida das pessoas. Seja na esfera da ciência, das artes, do direito e da religião e na solidariedade. O lebenswelt está mais preocupado com os aspectos cotidianos dos agentes sociais do que com a organização do poder do estado e sua administração. Por isso que o agir comunicativo habermasiano consegue cumprir o seu papel de descentralizadora da razão e, como o autor afirma, é fonte integração social. Segundo Habermas (1997, p. 111-112), "a prática comunicativa cotidiana, na qual o mundo da vida certamente está centrado, resulta, com a mesma originalidade, do jogo entre reprodução cultural, integração social e socialização".

O autor, através da democracia deliberativa, critica a forte oposição entre "a teoria dos sistemas" e o "mundo da vida". Os sistemas são responsáveis pela administração, pela burocracia dos governos, pela economia e pelo mercado. O "mundo da vida" está intrinsecamente ajustado às relações do convívio social. Para isso, é indispensável a ideia de solidariedade e de uma sociedade que busca ajuda mútua entre os cidadãos com a mesma finalidade, o bem comum, sendo fundamental a garantia dos 
direitos humanos por um Estado de direito democrático legitimado pela soberania popular.

Com esta perspectiva, o autor busca solucionar este problema propondo uma separação dos tipos de racionalidade, tanto comunicativa quanto sistêmica ou instrumental, respeitando os limites para que o sistema não invada o "mundo da vida" e desarticule as forças responsáveis pela solidariedade e pela compaixão entre indivíduos que participam de uma rede de inter-relacionamentos. Portanto, é a partir de uma dimensão dialogal, formada pela opinião e pela vontade, que os indivíduos são instigados a resolver problemas através da ideia de "bons argumentos" e, assim, poderem alcançar uma melhor ligação entre o mundo objetivo e o mundo subjetivo e social. O agir comunicativo assume, portanto, na sociedade, um caráter da busca e da consolidação de pressupostos fundamentados nos acordos mútuos.

Para Habermas (1997), é possível estabelecer uma ligação entre o "sistema" e os subsistemas do dinheiro e do mercado com o "mundo da vida". Isto só seria possível através de um reordenamento da razão, por meio de uma racionalidade comunicativa. É neste sentido que a democracia deliberativa forma uma alternativa que propõe e concentrar-se nos discursos e processos intersubjetivos de entendimento entre os cidadãos livres e iguais, mas não descarta o poder administrativo, pelo contrário, interage com ele por meio das esferas públicas, razão por que temos a ideia de sociedade civil forte.

A deliberação oferece a oportunidade de envolver, além de ambos os recursos do dinheiro e do poder administrativo, um terceiro recurso, o da solidariedade, que é formado comunicativamente. Desta forma, as qualidades argumentativas, por meio de processos de deliberação, trazem adicionalmente momentos de racionalidade no processo político, que não têm chance de transformar o processo deliberativo numa mera negociação política de acordos de interesses pré-estabelecidos.

$\mathrm{Na}$ democracia deliberativa o sistema político não é mais o centro da sociedade, mas a razão comunicativa que se expressa na capacidade que os indivíduos têm de argumentar numa esfera pública e produzir "bons argumentos". A esfera pública tem o poder de influenciar os processos políticos, inclusive o próprio aparato estatal e administrativo. A democracia deliberativa coloca o peso maior na solidariedade, afirmando-se em relação ao sistema da economia, do poder administrativo e dos subsistemas do dinheiro e do mercado. Uma nova visão de racionalidade comunicativa, segundo a qual o recurso da solidariedade está em pé de igualdade com os outros dois recursos, tendo, muitas vezes, que se afirmar diante deles.

Dessa compreensão democrática, resulta, por via normativa, a exigência de um deslocamento dos pesos que se aplicam a cada um dos elementos na relação entre os três recursos a partir dos quais as sociedades modernas satisfazem sua carência de integração e direcionamento, a saber: o dinheiro, o poder administrativo e a solidariedade. (HABERMAS, 2004, a, p. 289).

Desta forma a racionalidade comunicativa ligada a democracia habermasiana se afasta dos pressupostos da política focalizada na decisão. A democracia deliberativa também é colocada como alternativa em relação aos chamados modelos normativos de democracia: o liberalismo e o republicanismo, mas que se distingue destes dois tipos de política por ter uma visão de sociedade não centralizada no Estado. A deliberação também valoriza e redimensiona a esfera pública que é central para o seu pleno desenvolvimento.

A democracia deliberativa é normativa, pois desenvolve os procedimentos, porém sem os centralizar nas decisões políticas, mas na argumentação, tendo como 
referencial a teoria do discurso. Segundo Habermas (1997, p. 21) os procedimentos funcionam assim: "a procedimentalização da soberania popular e a ligação do sistema político às redes periféricas da esfera pública política implicam a imagem de uma sociedade descentrada".

A partir da teoria do discurso, a descentralização política torna-se evidente. Pode-se então compreender que esta visão, direcionada para uma sociedade amplamente racional, muda em si também os processos da formação política e supera em muito as próprias relações políticas e econômicas. A compreensão de uma política que busca o entendimento entre sujeitos racionais tem como objetivo uma racionalidade comunicativa, transformando a imagem de uma sociedade complexa e sistêmica numa sociedade amplamente politizada que discute seus problemas para chegar ao bem comum.

A crise de legitimação do Estado moderno é amplamente discutível na sociedade, porém Habermas busca aspectos e sinais positivos através da sua teoria do agir comunicativo que leva em consideração as capacidades dialógicas dos cidadãos. A chamada modernidade é marcada por uma profunda desarticulação das forças propulsoras da vida social. A "razão instrumental" tem sido, ao longo deste período, marcante para o aumento gradativo da problemática sectária da vida social, posto que tem sido instrumento forte para a ruptura entre vida social, civil e política, bem como um mecanismo forte de dominação e de alienação das forças e das ideias de libertação.

$\mathrm{Na}$ modernidade a racionalidade está focalizada na técnica pela ciência que deveria estar a serviço da humanidade na busca de uma razão subjetiva que pudesse compreender os sujeitos com suas particularidades ou individualidades. A razão comunicativa, na perspectiva da ética do discurso, busca fazer uma interação entre uma racionalidade subjetiva e objetiva, ou seja, uma ponte que una a teoria dos sistemas e a vida social. Isto, é claro, com a preocupação de distinguir a função de cada uma para que não aconteça que o próprio sistema sobrecarregue o "mundo da vida". Não podemos descartar a importância dos sistemas que são vitais para a organização e para o pleno funcionamento administrativo e econômico do Estado moderno. Já o "mundo da vida" é responsável pela interação e pela articulação entre os indivíduos através da solidariedade.

No "mundo da vida" os indivíduos estão livres da mecanização ou de uma linguagem superficial e indireta. Com o agir comunicativo as capacidades interativas da linguagem são utilizadas diretamente por parte de sujeitos ativos e livres para expressarem suas ideias, pensamentos, formarem opinião pública e articularem debates públicos. Com isso, uma finalidade é traçada para o melhor ordenamento de uma sociedade civil plenamente responsável de direitos e deveres. O "agir comunicativo" nos aproxima da racionalidade e, portanto, dá-nos pistas para conhecer a problemática que envolve a própria modernidade, superando, assim, a crise em decorrência da "colonização do mundo da vida"3 pelo sistema.

É nesse sentido que Habermas (1991b) reafirma o "mundo da vida" como campo fértil para o uso de uma linguagem do cotidiano e resgata o conceito de "mundo da vida" que atua não somente na subjetividade das ciências, na subjetividade do ser psíquico e no interior do eu transcendental, mas também no mundo fenomenológico no ser físico e do cotidiano, dos códigos da linguagem e da interação dos sujeitos uns com os outros.

Habermas tem uma visão apurada desta desarticulação e sedimentação da sociedade como uma racionalidade que saiu dos trilhos. Assim, ele pretende fazer uma distinção delineada entre o chamado potencial racional implícito na cultura moderna e os processos racionais de transformação na modernidade. 
A cultura moderna ocasionou mudanças no estilo de vida das pessoas. Segundo Habermas, há uma falta de interação entre as esferas sociais pública e privada. Mas com o aumento de uma consciência racional, fruto da razão comunicativa, ocorre um avanço da racionalidade nas sociedades. O diagnóstico da sociedade moderna também é marcado por uma crescente e desordenada expansão dos subsistemas do dinheiro e do mercado na sociedade e que gerou a "colonização do mundo da vida".

Ainda segundo a teoria da comunicação de Habermas, que se inter-relaciona com a própria visão de uma modernidade que almeja uma razão descentralizada, a sua teoria da ação comunicativa gerou uma nova moralidade com um discurso voltado também para uma metodologia nas ciências sociais, podendo-se observar a melhor compreensão entre o "agir comunicativo" e a "razão prática".

Desta forma, Habermas busca superar as controvérsias na moral contemporânea e filosófica, combatendo os diversos equívocos que apontam para a deficiência da legitimidade das teorias políticas modernas, de modo especial, as deficiências do modelo democrático liberal e republicano. No entanto, ele utiliza elementos de ambas as teorias políticas, tanto a liberal quanto a republicana, para formular sua teoria de democracia deliberativa.

O modelo deliberativo habermasiano é do tipo argumentativo e, é neste sentido que os pressupostos culturais da sociedade e da ética do discurso se tornam essenciais, mas se afastam do modelo liberal e republicano por não estarem focalizados nas tomadas de decisão, mas na argumentação, na ideia do bom argumento. Habermas explica o desenvolvimento da democracia deliberativa, tomando elementos de ambos os modelos normativos de democracia, mas compondo-os de modo novo. Segundo ele, "a teoria do discurso, que atribui ao processo democrático maiores conotações normativas do que o modelo liberal, as quais, no entanto, são mais fracas do que as do modelo republicano, assumem elementos de ambas as partes, compondo-os de modo novo" (HABERMAS, 1997, p. 20-21).

O liberalismo e o republicanismo como modelos normativos de democracia estão centralizados nas tomadas de decisão, ignoram a argumentação pública e têm sua estruturação institucional nos aparatos da administração pública e sistêmica, como no liberalismo político, Habermas propõe um terceiro modelo de democracia intitulado "democracia deliberativa".

Portanto, é neste contexto que a esfera pública se torna central para a democracia deliberativa, pois é a partir da esfera pública que as discussões se tornam públicas e, consequentemente, ganham força; é forjada uma nova identidade de democracia que tem na "razão pública" a imagem de uma sociedade mais justa.

\section{CONSIDERAÇões FINAIS}

De acordo com Habermas, a ação comunicativa é capaz de dar suporte a uma política inclusiva. Isto se dá através do diálogo e dos interesses dos cidadãos e cidadãs com uma prática "reconciliadora" na sociedade. Neste sentido a discussão pública é fundamental, sendo ampliada pela impressa que nas suas origens estava sob o controle da burguesia. Por isso ela se limitou a uma organização da sociedade centrada no poder administrativo de forma sistêmica e na busca de seus interesses.

Em análise, este antagonismo e busca de privilégios acelerou a teria dos sistemas e a colonização do mundo da vida.

A partir da política habermasiana e a esfera pública uma nova ideia de sociedade surge, caracterizada pelo discurso livre e pelo debate público, tirando o peso do 
aparelhamento estatal e sistêmico e se ancorando nos fundamentos da comunicação. Desta nova configuração de espaço público faz-se valer de uma racionalidade argumentativa, capaz de defender suas pretensões de validade e inteligibilidade, como meio de acesso a todos.

Portanto estas ideias lançadas pelo autor e refletidas a partir de uma categoria de esfera pública burguesa procuram desenvolver um modelo de racionalidade - a razão comunicativa - para oferecê-lo como fundamento das práticas e das interações humanas em um espaço público. A racionalidade comunicativa é aquela que estrutura discursos capazes de justificação, argumentativos, finitos ou falíveis (criticáveis). Esta razão está na base de uma "formação racional da vontade" onde o filósofo de "Consciência moral e agir comunicativo", "Direto e Democracia: Entre a validade e a Facticidade" e da "Mudança Estrutural da Esfera Pública" enxerga um alicerce da moral e da política. Consequentemente os seus argumentos são a base e condição do discurso racional para resolver questões práticas em uma esfera pública livre e inclusiva.

\section{REFERÊNCIAS}

ABBAGNANO, Nicola. Dicionário de Filosofia. 4a . Ed. São Paulo: Martins Fontes, 2000.

ARISOTELES. Ética a Nicômaco. Tradução de Leonel Vallandro e Gerd Borhheim, Abril Cultural $1^{a}$ edição, São Paulo, 1973.

AVRITZER, Leonardo. Teoria democrática e deliberação pública em Habermas e Ralws. Departamento de Ciência Política da UFMG, 2000.

AVRITZER, Leonardo. A moralidade da democracia. Belo Horizonte: Perspectiva/UFMG, 1996.

BEISER, Frederick C. (Org.) et ali. Hegel. Tradução de Guilherme Rodrigues Neto. São Paulo: Ideias \& Letras, 2014. Companions \& Companions)

BOBBIO, Norberto. O futuro da democracia. Tradução de Marco Aurélio Nogueira. São Paulo: Paz e Terra 2000.

BOHMAN, James. Public Deliberation: pluralism, complexity, and democracy. Cambridge: The MIT Press, 1996.

BRENNAND, Edna Gusmão de Goés. Democracia e construção do espaço público em Jurgen Habermas. In BRENNAND, Edna Gusmão de Goés, et al. Washington (org.) Diálogos com Jurgen Habermas. João Pessoa, Ed. Universitária/UFPB, 2006, p. 31-45.

FARIA, Cláudia Feres. Democracia deliberativa: Habermas, Cohen e Bohman. Lua Nova. 2000, $\mathrm{n}^{\mathrm{o}} .50$, p. $47-68$.

GARCIA, Vileni. Jurgen Habermas: uma concepção deliberativa de democracia. In. LYRA, Rubens Pinto. (org.). Teoria Política - do Renascimento à contemporaneidade, João Pessoa: Ed. Universitária, 2007, p. 192-207.

HABERMAS, Jurgen. A Lógica das Ciências Sociais. Tradução de Marco Antônio Casa Nova. Petrópolis: Vozes, 2009.

HABERMAS, Jurgen. Between Facts and Norms. Cambridge: Mit Press, 1995.

HABERMAS, Jurgen. Comentários à ética do discurso. Tradução: Gilda Lopes Encarnação. Lisboa: Instituto Piaget, Editorial Minerva, 1991a.

HABERMAS, Jurgen. Consciência moral e agir comunicativo. Tradução de Guido A. de Almeida. Rio de Janeiro: Tempo Brasileiro, 2003 a .

HABERMAS, Jurgen. Crise de legitimação no capitalismo tardio. Rio de Janeiro: Tempo Brasileiro, 1980.

HABERMAS, Jurgen. Direito e democracia: entre facticidade e validade. Vol. I e II. Tradução de Flávio Beno Siebeneichler. Rio de Janeiro: Tempo Brasileiro, 1997.

HABERMAS, Jurgen. Entre Naturalismo e Religião. Estudos Filosóficos. Tradução de Flávio Beno Siebeneichler: Rio de Janeiro: Tempo Brasileiro, 2007.

HABERMAS, Jurgen. Mudança estrutural da esfera pública: investigação quanto a uma categoria da sociedade burguesa. Tradução de Flávio R. Kothe. Rio de Janeiro: Tempo Brasileiro, $2003 \mathrm{~b}$.

HABERMAS, Jurgen. O Discurso Filosófico da Modernidade. Trad. de Luiz Sérgio Raposa Rodnei Nascimento. São Paulo: Martins Fontes, 2000.

HABERMAS, Jurgen. Passado como futuro. Tradução Flávio Beno Siebeneichler. Rio de Janeiro: Tempo Brasileiro, 1993. 
HABERMAS, Jurgen. Pensamiento postmetafisico. Madrid: Taurus, 1990a.

HABERMAS, Jurgen. Perfiles Filosóficos. Madrid: Taurus, 1971

HABERMAS, Jurgen. Racionalidade e Comunicação. Tradução Paulo Rodrigues. Lisboa: Edições 70, 1996.

HABERMAS, Jurgen. Textos e contextos. Tradução de Sandra Lippert Vieira. Lisboa: Instituto Piaget, Stória Editores, $1991 \mathrm{~b}$.

HABERMAS, Jurgen. Verdade e justificação. Ensaios filosóficos. Tradução de Milton Camargo Mota. São Paulo: Edições Loyola, 2004 b.

HABERMAS, Jurgen. A inclusão do outro. Estudos de teoria política. $2^{\text {a }}$ ed. São Paulo: Edições Loyola, 2004 a.

HABERMAS, Jurgen. Teoria de la acción comunicativa, T I. Racionalidade de la acción y racionalización social. Buenos Aires: Taurus, 1990 b.

HERRERO, Francisco Javier. Ética do discurso. UFMG, 2000.

HERRERO, Francisco Javier. Habermas: Sociologia. (Orgs. Barbara Freitag e S. P. Rouanet). São Paulo: Ática, 1980.

HERRERO, Francisco Javier. A pragmática transcendental como filosofia primeira. In: Síntese. Nova Fase, vol. 24, no 79, 1997, p. 497-512.

HERRERO, Francisco Javier. O discurso na visão da pragmática trascendental. In: Fundamentos e dimensões da análise do discurso - Hugo Mari (Org). Belo Horizonte: Fale-UFMG, 1999, p. 59-71.

KANT, Immanuel. Textos Seletos. Tradução de Emmanuel Carneiro Leão. 3. ed. Petrópolis-RJ: Vozes, 2005.

KANT, Immanuel. Fundamentação da Metafísica dos Costumes. Tradução de Leopoldo Holzbach. São Paulo: Martin Claret, 2003. .

LOCKE, John. Segundo tratado sobre o governo. Tradução de Anoar Aiex e E. Jacy Monteiro. 3. ed. São Paulo: Abril Cultural, 1983.

LUBENOW, Jorge Adriano. A categoria de esfera pública em Jürgen Habermas: para a reconstrução da autocritica. 2 ed. Curitiba Paraná, 2015.

LUHMANN, Niklas. Legitimação pelo procedimento. Trad. Maria da Conceição Corte-Real. Brasília: Ed. Universidade de Brasília, 1980. (Coleção pensamento político, 15).

MAIA, Rousiley Celi Moreira; FERNANDES, Adélia Barroso. O Movimento Antimanicomial como agente discursivo na esfera pública política. Revista Brasileira de Ciências Sociais. Anpocs, No 48, 2002, p. 157-172.

MARX, Karl. O Rendimento e Suas Fontes. Tradução de Edgard Malagodi. São Paulo: Nova Cultural, 2000.

OLIVEIRA, Manfredo. Filosofia política contemporânea. Petrópolis, Rio de Janeiro: Vozes, 2003.

RAWLS, John. Political Liberalism. New York: Columbia University Press, 1993.

RAWLS, John. Uma teoria da justiça; Nova tradução, baseado na edição americana revista pelo autor, Jussara Simões; revista técnica e de tradução Álvaro de Vita. $3^{\circ}$ edição. São Paulo: Martins Fontes, 2008.

REIS, Fábio Wanderley. Cidadania, Mercado e Sociedade Civil. In: Teoria e Utopia. São Paulo, Edusp, 2000.

ROCHLITZ, Rainer. O Uso público da razão. Rio de Janeiro: Edições Tempo Brasileiro, 2005.

ROUSSEAU, Jean Jacques. Do contrato social; tradução de Lourdes Santos Machado; Introdução e notas de Paul Arbouse - Bastilde e Lourival Gomes Machado. 3. ed. São Paulo: Abril Cultural, 1983. 